\title{
Computational modelling of dynamic loads of a container under viscous interaction with a flat wagon in sea transport
}

\author{
Alyona Lovska ${ }^{1}$, Oleksij Fomin ${ }^{2}$, Václav Píštěk ${ }^{3}$, Pavel Kučera ${ }^{4}$ \\ ${ }^{1}$ Department of Wagons, Ukrainian State University of Railway Transport, Kharkiv, Ukraine \\ ${ }^{2}$ Department of Wagons and Wagonriage Facilities, State University of Infrastructure and Technologies, \\ Kyiv, Ukraine \\ ${ }^{3,4}$ Department of Internal Combustion Engines, Brno University of Technology, Brno, Czech Republic \\ ${ }^{2}$ Corresponding author \\ E-mail: ${ }^{1}$ alyonalovskaya.vagons@gmail.com,2fominaleksejviktorovic@gmail.com,3pistek.v@fme.vutbr.cz, \\ ${ }^{4}$ kucera@fme.vutbr.cz
}

Received 30 April 2020; accepted 6 May 2020

DOI https://doi.org/10.21595/vp.2020.21441

Check for updates

Copyright (C) 2020 Alyona Lovska, et al. This is an open access article distributed under the Creative Commons Attribution License, which permits unrestricted use, distribution, and reproduction in any medium, provided the original work is properly cited.

\begin{abstract}
The article deals with the computational modelling of dynamic loads of a container under viscous interaction with a flat wagon transported by a train ferry. The calculation was made with the finite element method in CosmosWorks software. The study defined acceleration fields for the carrying structure of a container and a flat wagon. It was established that the maximum variance percent between the accelerations obtained by theoretical and computational modelling was $17.7 \%$. The research will contribute to higher efficiency of combined transportation along international transport corridors.
\end{abstract}

Keywords: wagon, carrying structure, combined transportation, dynamics, strength.

\section{Introduction}

Development of competitive environment in the rail transportation market requires implementation of combined transport systems. Train ferries are widely used by countries which are integrated in the international transport environment. Nowadays train ferries transport not only wagons and cars but also trains of combined transport. And special attention should be given to the strength of containers regarding flat wagon frames. Containers are fixed on flat wagons by a standard diagram, i.e. with fittings installed on fitting stops. However, such an interaction pattern does not ensure the required stability of containers within intermodal trains in sea transportation. Therefore, there is a need to improve the carrying structure of a flat wagon to ensure safe transportation of containers by train ferries.

The effect of the mass centre of a flat wagon on the metacentric height of a ferry is studied in [1]. The study suggests an algorithm to evaluate the impact of the position of a container mass centre on the stability of a container ship. The dynamic stability of the freight under loading and transporting in a container is defined in [2]. The research was conducted for package cargo. The studies do not consider the stability of a container transported within a combined train by sea. Techniques for loading and fixation of steel rolls in containers under rail/sea transportation are considered in [3]. Peculiarities of design of containers for long-length freight transportation are considered in [4]. The strength calculation for the carrying elements of a container under the loads from pipes transported was made with the finite element method. But the studies do not consider the modelling of dynamic loads of a container in train ferry transportation. Peculiarities of design of containers used for transportation of fruit and vegetable products are given in [5]. The article gives requirements for a container body, suggests the design, and presents the strength calculation. It should be mentioned that the dynamic loading of containers is not studied, and strength characteristics are defined with consideration of the normative loads. A review of basic problems of the rolling stock dynamics related to the traffic safety is presented in [6]. The study deals with 
the basic criteria used to evaluate the rolling stock safety according to standards adopted in different countries. But it does not concern the safe operation of containers within combined trains transported by train ferries.

Peculiarities of the dynamic loading of trains transported by train ferries are given in $[7,8]$. The research was conducted by mathematic modelling and proved by computer modelling. However, the authors do not study the dynamic loading of containers, and do not develop methods for ensuring their stability in transportation by train ferries. Other methods that can be effectively used to research dynamic systems of a similar kind are described in [9-13].

It should be noted that measures to reduce the dynamic loading of platform wagons with containers during transportation on railway ferries have not yet been properly consecrated. Therefore, the research presented in this article is relevant and has a scientific novelty.

\section{Computational model of container-wagon interaction}

The authors proposed the improved carrying structure of a flat wagon to ensure the required stability of containers transported within combined trains by train ferries. The study deals with special under structures installed on carrying structures of flat wagons, similar to ones used for a 13-9744 flat wagon (Fig. 1).

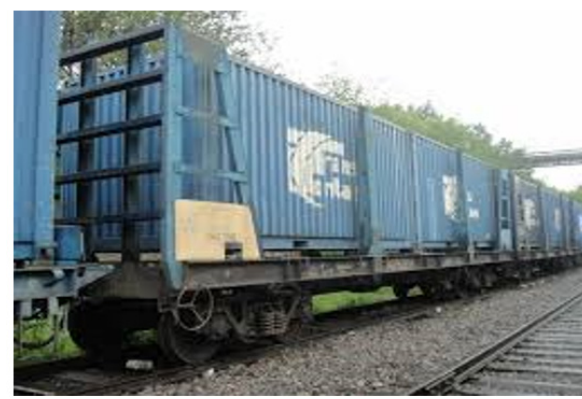

a)

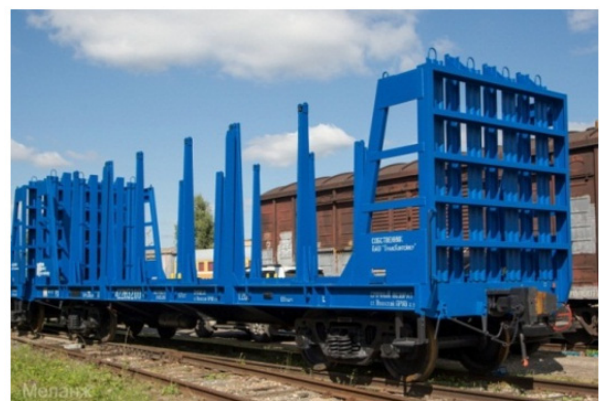

b)

Fig. 1. The wagon model 13-9744 a) in loaded state; b) in empty state

The dynamic loading of a container can be decreased by placing a viscous material between the side walls and the vertical surfaces of the superstructure. The computational modelling of dynamic loads on a loaded flat wagon with consideration of the solutions suggested was based on spatial models in SolidWorks software (Fig. 2).

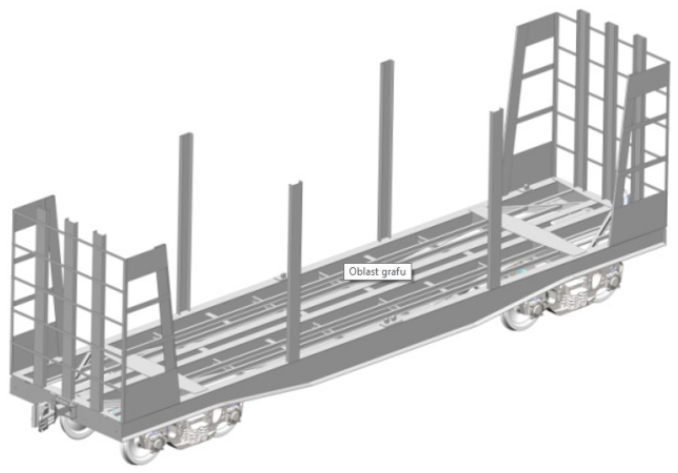

a)

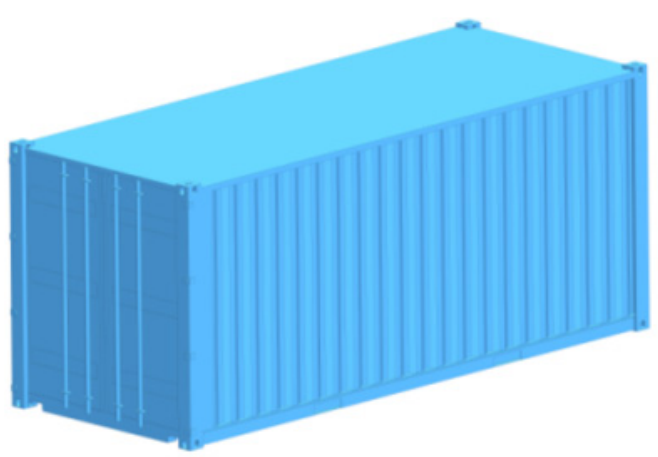

b)

Fig. 2. The spatial models of a flat wagon and a container a) flat wagon; b) 1CC container

The calculation was performed using the finite element method in CosmosWorks software 
[14-16]. Spatial isoparametric tetrahedrons were used to build the finite element model (Fig. 3). The optimal number of finite elements was determined by the graphical-analytical method [17-20]. The basic characteristics of the model are given in Table 1.

The carrying structure material was $09 \mathrm{G} 2 \mathrm{~S}$, the yield stress $\sigma_{T}=345 \mathrm{MPa}$ and the strength limit $\sigma_{T}=490 \mathrm{MPa}[21-23]$.

Table 1. The characteristics of the finite element model

\begin{tabular}{|c|c|}
\hline Number of elements & 883801 \\
\hline Number of nodes & 302512 \\
\hline Maximal size of an element, mm & 100.0 \\
\hline Minimal size of an element, mm & 20.0 \\
\hline Maximal ratio of elements' sides & 9027.4 \\
\hline Percentage of elements with a ratio of sides less than three & 29.7 \\
\hline Percentage of elements with a ratio of sides less than ten & 24.2 \\
\hline Minimal number of elements in a circle & 9 \\
\hline The ratio of an increase in the size of an element & 1.7 \\
\hline
\end{tabular}

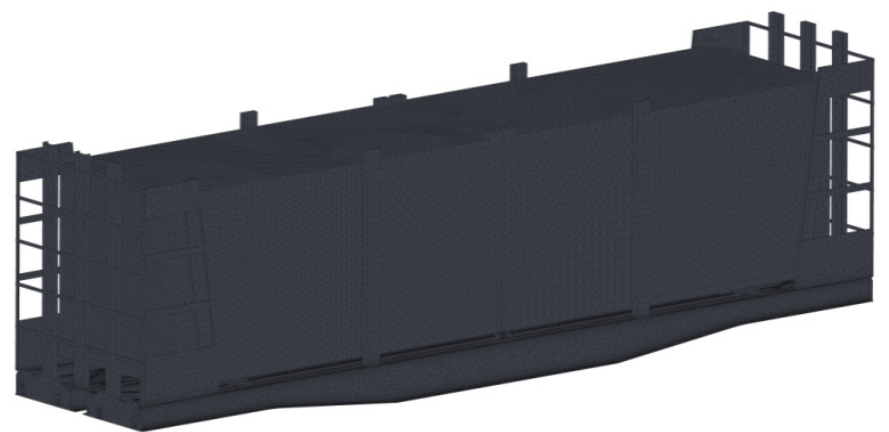

Fig. 3. The finished model of the carrying structure of a wagon loaded with containers

The design scheme considered that the carrying structure was affected by the vertical load of the container gross weight $P_{g w}$, the tension of chain ties $P_{f}$, the wind load $P_{w}$, as well as the horizontal load from the add-on container $P_{h}$, due to fluctuations in the wagon (Fig. 4). The container was subjected to the vertical static load $P_{v}^{c}$, the horizontal load in the areas of interaction with add-on $P_{h}^{c}$, as well as the wind load on the side surface $P_{w}^{c}$.

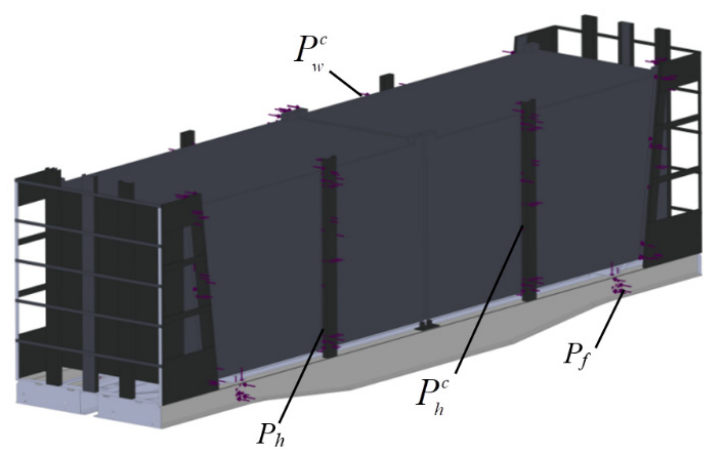

Fig. 4. The design scheme of the carrying structure of a wagon loaded with containers

The calculations were performed for a container of standard size 1CC with a gross weight of 24 tons. In this case, the force from the tension of the chain ties was determined by mathematical modeling of the dynamic loading of a flat car with containers during sea transportation. This load was decomposed into three components, taking into account the catch of the location of chain ties 
in space. The wind load is assumed to be $1.47 \mathrm{kPa}$ in accordance with the hydrometeorological conditions of the Black Sea. The load $P_{h}$ is the resulting horizontal component of the acceleration due to gravity and the acceleration acting during the oscillations of the vessel. In this case, the estimated angle of inclination from the action of static wind pressure on the surface projection of the vessel for the Black Sea was $12.2^{\circ}$.

The model was fixed in the areas of support on the wagon, as well as the working surfaces of mechanical stop-jacks. Thus, it was fitted with pads, the area of which was equal to that of the working surfaces of the stop-jacks.

A viscous material of the viscous resistance coefficient $1.2 \mathrm{kNs} / \mathrm{m}$ was placed between the interaction zones of the container and the superstructure of the wagon. The calculation results are shown in (Fig. 5). The maximum acceleration affected the upper part of a container along the central axis of symmetry of the carrying structure of a wagon was about $2.6 \mathrm{~m} / \mathrm{s}^{2}$.

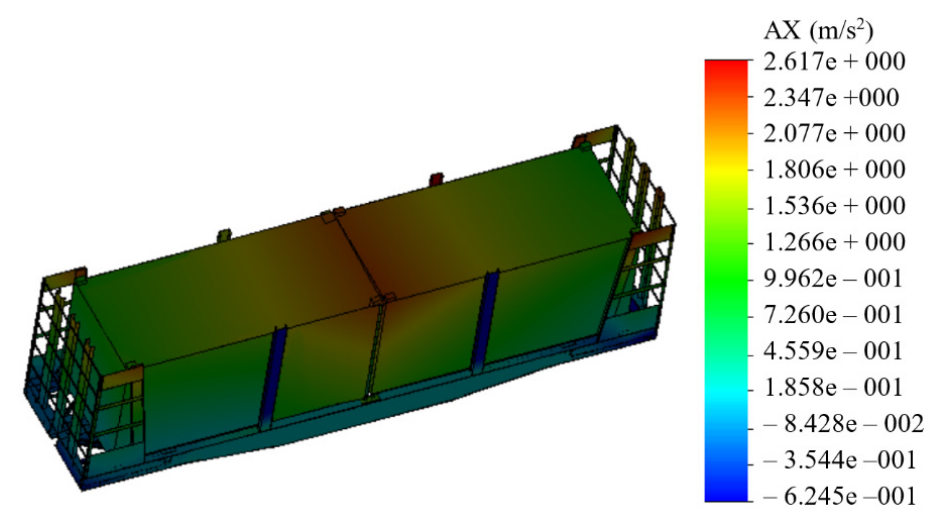

Fig. 5. The distribution of acceleration fields for the carrying wagon structure loaded with containers

The accelerations on the container obtained by theoretical and computational modelling are shown in Fig. 6. It demonstrates that the maximum variance percent between accelerations is $17.7 \%$ at the roll angle $10^{\circ}$.

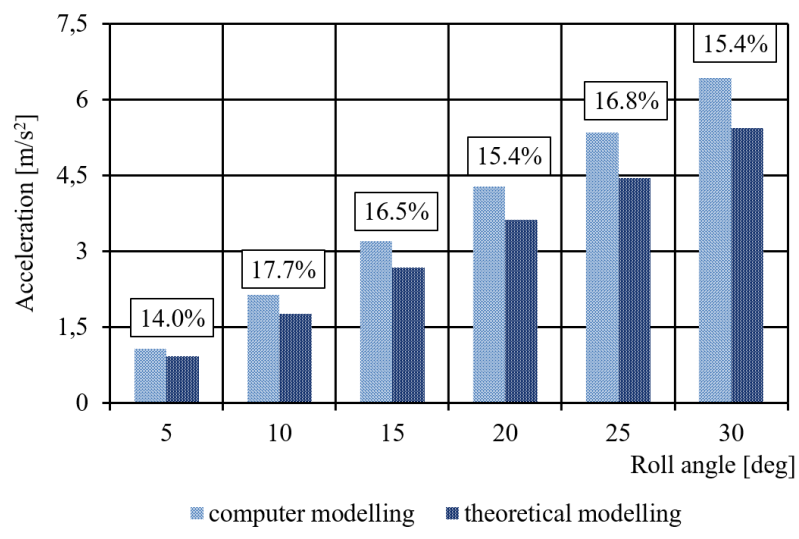

Fig. 6. The accelerations of a container placed on the wagon

Using the designed model the authors defined the critical oscillation frequencies of the carrying structure of a flat wagon loaded with containers in train ferry transportation. The results of the calculation are given in Table 2.

Table 2 demonstrates that the critical oscillation frequencies are within the admissible range. The use of viscous connection among wagons and containers transported by train ferries reduced 
the dynamic loads of the flat wagon carrying structure and improved the traffic safety.

Table 2. The critical oscillation frequencies of the carrying structure of a flat wagon loaded with containers in train ferry transportation

\begin{tabular}{|c|c|c|c|c|c|c|c|c|c|c|}
\hline Mode & 1 & 2 & 3 & 4 & 5 & 6 & 7 & 8 & 9 & 10 \\
\hline Frequency $[\mathrm{Hz}]$ & 12.58 & 13.63 & 13.69 & 13.89 & 13.95 & 14.49 & 15.06 & 21.16 & 21.37 & 21.47 \\
\hline
\end{tabular}

\section{Conclusions}

The authors designed the improved carrying structure of a flat wagon to ensure the required stability of a container within combined trains transported by train ferries. The study deals with special under structures installed on the carrying structure of a flat wagon similar to ones used for a 13-9744 flat wagon. The viscous material between the side walls and vertical surfaces of the superstructures can decrease the container dynamic load. The computational modelling of container dynamic loads was made with consideration of a new interaction scheme. The maximum acceleration applied to the container was about $2.6 \mathrm{~m} / \mathrm{s}^{2}$. The maximum percentage of discrepancy between the accelerations obtained by theoretical and computer modelling was $17.7 \%$. The research conducted will improve the combined transport efficiency and contribute to development of new wagon designs.

\section{Acknowledgements}

The present study was conducted within the framework of the scientific topic of young scientists "Innovative principles of creation of resource-saving structures of railroad cars by taking into account the refined dynamic loads and functional-adaptive flash concepts", which is funded by the state budget of Ukraine in 2020 and the authors gratefully acknowledge funding from the Specific research on BUT FSI-S-20-6267.

\section{References}

[1] Tsarik R. S., Akmaykin D. A. Assessment of the influence of the container's center of gravity on the metacentric height of the container ship. Vestnik gosudarstvennogo universiteta morskogo I rechnogo flota imeni admirala S. O. Makarova, Vol. 40, Issue 6, 2016, p. 58-70, (in Russian).

[2] Bracht E., Queiroz T., Schouery R., Miyazawa F. Dynamic cargo stability in loading and transportation of containers. IEEE International Conference on Automation Science and Engineering, 2016, p. 227-232.

[3] Lv H., Yang Z., Zhou Y. Measures of loading and securing steel coils in containers in rail-water combined transport. 4th International Conference on Transportation Engineering, 2013.

[4] Panasenko N. N., Yakovlev P. V. Designing containers for sea transportation of long pipes. Vestnik Astrahanskogo gosudarstvennogo tehnicheskogo universiteta, Morskaya Tehnika i Tehnologiya, Vol. 3, 2014, p. 97-107, (in Russian).

[5] Ibragimov N. N., Rahimov R. V., Hadzhimuhamedova M. A. Development of the design of a container for transportation of fruits and vegetables. Molodoy Uchenyiy, Vol. 21, Issue 101, 2015, p. $168-173$.

[6] Kardas-Cinal E. Selected problems in railway vehicle dynamics related to running safety. The Archives of Transport, Vol. 31, Issue 3, 2014, p. 37-45.

[7] Fomin O., Lovska A., Melnychenko O., Shpylovyi I., Masliyev V., Bambura O., Klymenko M. Determination of dynamic load features of tank containers when transported by rail ferry. Eastern-European Journal of Enterprise Technologies, Vol. 5, Issue 7(101), 2019, p. 19-26.

[8] Fomin O., Lovska A., Masliyev V., Tsymbaliuk A., Burlutski O. Determining strength indicators for the bearing structure of a covered wagon's body made from round pipes when transported by a railroad ferry. Eastern-European Journal of Enterprise Technologies, Vol. 1, Issue 7, 2019, p. 33-40.

[9] Kučera P., Píštěk V. Truck vibrations caused by rotating shaft deflection. Journal of Vibroengineering, Vol. 19, Issue 7, 2017, p. 5361-5373. 
[10] Píštěk V., Klimeš L., Mauder T., Kučera P. Optimal design of structure in rheological models: an automotive application to dampers with high viscosity silicone fluids. Journal of Vibroengineering, Vol. 19, Issue 6, 2017, p. 4459-4470.

[11] Zajac R., Prokop A., Řehák K. Determination of the modal parameters on the thin flat structures. Vibroengineering Procedia, Vol. 18, 2018, p. 91-95.

[12] Tůma J., Kočí P. Calculation of a shock response spectrum. 12th International Carpathian Control Conference (ICCC), Velke Karlovice, Czech Republic, 2011, p. 408-413.

[13] Tůma J., Kočí P. Calculation of a shock response spectrum. Colloquium Dynamics of Machines, Prague, Czech Republic, 2009, p. 408-413.

[14] Alyamovsky A. A. SolidWorks/COSMOSWorks 2006-2007 - Engineering Analysis by the Finite Element Method. DMK, Moscow, 2007, p. 784, (in Russian).

[15] Kurowski P. Engineering Analysis with SOLIDWORKS Simulation 2019. SDC Publications, England, 2019, p. 606.

[16] Weber M., Verma G. SolidWorks Simulation 2015 Black Book. 2ed. Edition, SDC Publications, England, 2015.

[17] Lovskaya A., Rybin A. The study of dynamic load on a wagon-platform at a shunting collision. Eastern-European Journal of Enterprise Technologies, Vol. 3, 2016, p. 4-8.

[18] Fomin O. V., Burlutsky O. V., Fomina Yu. V. Development and application of cataloging in structural design of freight wagons building. Metallurgical and Mining Industry, Vol. 2, 2015, p. $250-256$.

[19] Fomin O., Gerlici J., Lovska A., Kravchenko K., Prokopenko P., Fomina A., Hauser V. Durability determination of the bearing structure of an open freight wagon body made from round pipes during its transportation on the railway ferry. Communications-Scientific letters of the University of Zilina, Vol. 21, Issue 1, 2019, p. 28-34.

[20] Ravlyuk V., Ravliuk M., Hrebeniuk V., Bondarenko V. Process features and parametric assessment of the emergence of the excessive wear for the brake pads of freight car bogies. IOP Conference Series: Materials Science and Engineering, Vol. 708, 2019, p. 012025.

[21] Freight Wagons. General Requirements for the Calculations and Design of New and Upgraded 1520 mm (Non-Self-Propelled) Railcars. DSTU 7598:2014, 2014, (in Ukrainian).

[22] Freight Wagons. Strength and Dynamic Quality Requirements. GOST 33211-2014, 2014, (in Russian).

[23] Railway Applications - Structural Requirements of Railway Vehicle Bodies, Part 2: Freight wagons. EN 12663-2, 2010. 